\title{
Sarcoidosis simulating syringomas
}

\section{Sarcoidose simulando siringomas}

\author{
Diego Santos Rocha ${ }^{1}$ \\ Daniela Martins Bringel ${ }^{2}$ \\ Eli Balassiano ${ }^{3}$
}

\author{
Carolina Presotto ${ }^{2}$ \\ Lislaine Bomm ${ }^{1}$ \\ Maria de Fátima Guimarães Scotelaro Alves ${ }^{4}$
}

\begin{abstract}
Sarcoidosis is a granulomatous disease of unknown etiology. The skin is commonly affected. Cutaneous manifestations can mimic other diseases and autoimmune disorders. The dermatologist plays a critical role in elucidating the clinical diagnosis and assisting other specialists in the investigation of a systemic disease. We report a patient with typical cutaneous manifestation of sarcoidosis with pulmonary involvement.

Keywords: Granuloma; Sarcoidosis; Skin manifestations

Resumo: A sarcoidose é uma doença granulomatosa de etiologia desconhecida. A pele é comumente afetada. As manifestações cutâneas podem mimetizar outras afecções e desordens auto-imunes. Assim, o dermatologista assume papel fundamental para elucidar o diagnóstico clínico e auxiliar outros especialistas na investigação de uma doença sistêmica. Relatamos um caso de paciente com manifestação cutânea típica de sarcoidose associada com acometimento pulmonar. Palavras-chave: Granuloma; Manifestações cutâneas; Sarcoidose
\end{abstract}

\section{INTRODUCTION}

Sarcoidosis is a non infectious granulomatous disease of unknown etiology. Genetic, immunologic, environmental and infectious factors apparently participate in its pathogenesis. Several organs may be affected, which permits a wide spectrum of clinical manifestations. The skin is involved in about 20 to $35 \%$ of cases. Cutaneous sarcoidosis is present in innumerous forms, which can mimic other skin diseases and autoimmune disorders. Therefore, the dermatologist plays an important role in the diagnosis of the illness. We report a case of a sarcoidosis patient whose lesions are bilateral normochromic papules in the eyelid region, associated with pulmonary involvement.

\section{CASE REPORT}

Hypertensive female patient, black, 69 years old, with onset of bilateral normochromic papules in the upper and lower eyelid region, with discrete itching, 3 years ago (Figure 1). She denied any other symptoms. Two years ago she looked for assistance at the Dermatology Service and received the clinical diagnosis of cutaneous sarcoidosis, which was ratified by the histopathological examination. This revealed well delimited, non caseating granulomas in the dermis, with few lymphoid cells around epithelioid cells (Figure 2). The Ziehl-Neelsen and PAS staining techniques were negative, as well as the culture of biopsy material. Liver function, kidney function, hemogram, serum and urinary calcium, electrocardiogram, hands and feet X-rays without abnormalities. A chest radiograph revealed bilateral linear hypotransparencies in the lower third of lung parenchyma with bronchiectasis on the same topography. High resolution thorax tomography with contrast demonstrated multiple

Received on 30.03.2011

Approved by the Advisory Board and accepted for publication on 15.05.2011.

* Study carried out at the Teaching Hospital Pedro Ernesto - Universidade do Estado do Rio de Janeiro - HUPE (UERJ) - Rio de Janeiro (RJ), Brazil. Conflict of interest: None

Financial funding: None

Resident of the Dermatology Service, Universidade do Estado do Rio de Janeiro (UERJ) - Rio de Janeiro (RJ), Brazil Graduate student of the Dermatology Service, Universidade do Estado do Rio de Janeiro (UERJ) - Rio de Janeiro (RJ), Brazil.

Dermatologist - Preceptor of the Dermatology Service, Universidade do Estado do Rio de Janeiro (UERJ) - Rio de Janeiro (RJ), Brazil.

PhD from the Universidade Federal do Rio de Janeiro (UFRJ) - Adjunct Professor responsible for the Dermatopathology sector of the Dermatology Service, Universidade do Estado do Rio de Janeiro (UERJ) - Rio de Janeiro (RJ), Brazil. 


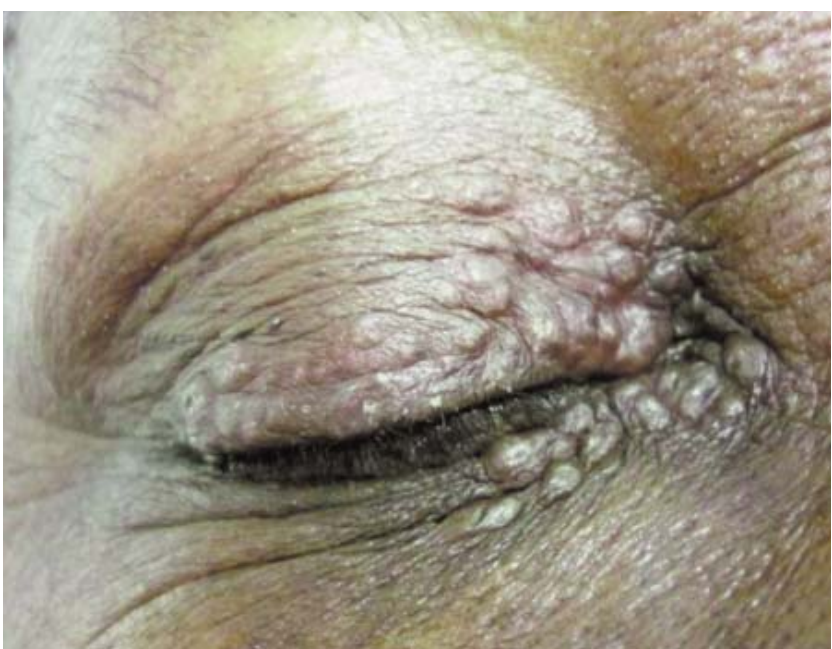

FiguRE 1: Sarcoidosis. Normochromic papules on right eyelid region

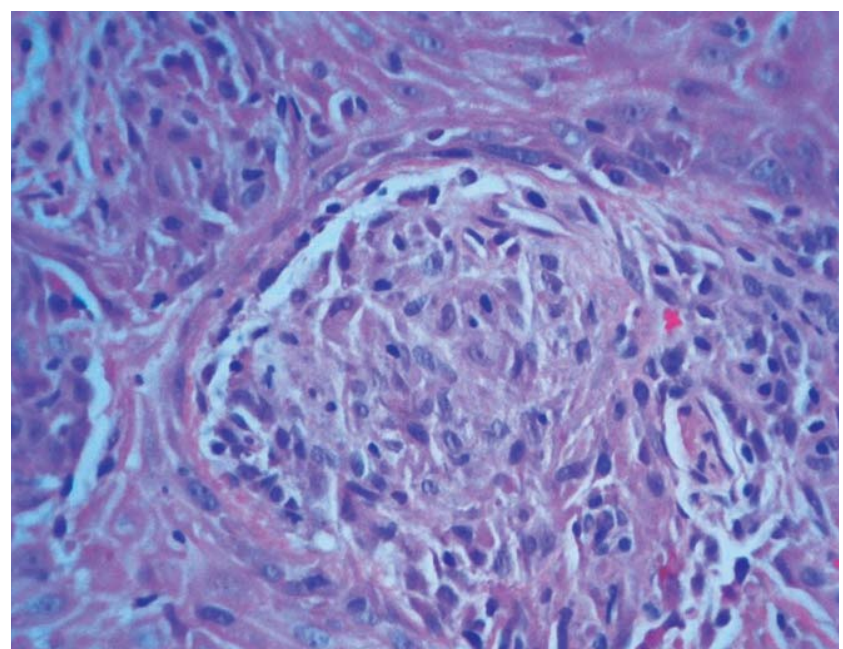

FIGURE 2: Sarcoidosis. Histiocytes with concentrically disposed eosinophilic cytoplasm form the granuloma, with few lymphocytes around it (HE, 400X)

Patients may be asymptomatic or have unspecismall lymph nodes in the lower pretracheal chain, besides opacities with ground glass attenuation associated with fine reticular bands and traction bronchiectasis in the lower lobes basal segments, which would be related to fibrosis. Spyrometry revealed light restrictive disorder and the ophthalmologic exam dod mot present alterations. In face of the cutaneous manifestations, the conduct adopted by the Dermatology Service was to orient the patient and observe the case, since the lesion did not present important esthetic/functional damage. However, due to the lung involvement, Pneumology optimized the treatment with prednisone $40 \mathrm{mg} / \mathrm{day}$ and azathioprine $50 \mathrm{mg} /$ day,with gradual improvement of respiratory function.

\section{DISCUSSION}

Sarcoidosis is a non infectious multisystem granulomatous disease of unknown etiology. Genetic, immunologic, environmental and infectious factorsseem to be related to its pathogenesis. ${ }^{1}$ The first case of lupus pernio was described by Besnier, in 1889. Ten years later, the Norwegian dermatologist Boeck observed epithelioid granulomas histologically, naming the afection "multiple benign sarcoid of the skin". In 1914, Schaumann reported systemic involvement of the disease. In honor of these authors, sarcoidosis is also called Besnier-Boeck-Schaumann disease., ${ }^{2,3}$

The incidence of sarcoidosis is greater in developed countries. In Brazil, the estimated incidence is $10 / 100,000$ inhabitants in $1985 .{ }^{4,5}$ Women are affected at the rate of 1.2:1 with predilection for the black race. ${ }^{6}$ Sarcoidosis affects young adults, preferably in the 25 to 40 year old age group, being rare in childhood. A second incidence peak is observed between 45 and 65 years of age. ${ }^{1}$ fic symptoms such as fever, emaciation, night swear and fatigue. Other symptoms depend on the organs affected by the disease, as lung (dry cough, dispnea, chest pain), eye (eye pain, vision disorders), skin, musculoskeletal system (joint pains, myalgia) and lymph node enlargement. Neurological, renal and cardiac symptoms are rare and, when they exist, they indicate severe disease. ${ }^{1,7}$

Some specific clinical pictures are described, as the Löfgren syndrome, which consists of the association of fever, iritis, bilateral hilar adenomegaly and erythema nodosum, and is associated with a benign course of the illness, with spontaneous resolution in $90 \%$ of the cases. Other classical syndromes are the Heerfordt-Waldenström syndrome, that presents with fever, parotid gland enlargement, anterior uveitis and facial paralisy, and Mikulicz syndrome, where the parotid, submandibular, sublingual and lacrimal glands are involved. In childhood, the classical involvement was composed of arthritis, cutaneous lesions and uveitis. ${ }^{1,7}$

The cutaneous disease occurs in $20-35 \%$ of the cases, enabling an early diagnosis due to the easiness in collectiong a biopsy for the histopathological exam. Sarcoidosis may present innumerous forms of cutaneous manifestations: maculo-papulous, nodular, plaque, erythemato-brownish, single or multiple lesions. Classicaly, in the diascopy of these lesions the "apple jelly" color is observed. The presence of midface erythematous and infiltrated lesion characterizes lupus pernio, of difficult treatment and that may lead to disfigurement. Subcutaneous sarcoidosis lesions where epithelioid granulomas are observed in the panniculus adiposus are named Darier-Roussy nodules, and it 
is suggested that this form of cutaneous sarcoidosis is related to systemic disease ${ }^{1,78}$ Other less usual forms include ulcerated, ichthyosiform, psoriasiform, hypopigmented, verrucous, perforating, mutilating, rosaceiform, sclerodermiform, mimicking lipodermatosclerosis, lichenoid and erythrodermic lesions and alopecia, cicatricial or not. ${ }^{1,7,9,10}$

Infiltration of scars and tattoos by epithelioid granulomas may occur as the initial manifestation of sarcoidosis or associated with systemic disease. ${ }^{1,7,9,11}$

The only skin lesion correlated with the prognosis if the erythema nodosum, that occurs in the acute phase and is associated with sarcoidosis of spontaneous resolution. The erythema nodosum is the unspecific manifestation of the disease, as the epithelioid granuloma cannot be observed histologically. Other unspecific manifestations are the eritema multiforme, pruritus, calcifications and ungual alterations associated or not to bone cysts.'

Histopathology revealed sarcoidal granuloma formed by concentrical disposition of epithelioid cells. Sarcoidal granulomas may present a loose lymphocyte halo on its periphery, which caused them to be named "nude granulomas", in contrast with tuberculoid granulomas where a dense lymphocytary infiltrate may be observed around those structures. caseating necrosis, characteristic of tuberculoid granulomas, is not observed in sarcoidal granulomas. Although they are not specific of sarcoidosis, asteroid corpuscles may be observed within giant cells (star-shaped collagen fibers) and Schaumann bodies (rounded, basophilic formations that seem to correspond to calcified lysosomes). The sarcoidosis diagnosis should only be made after special staining tests for mycobacteria and fungi, with their consequent negative demonstration, and absence of nervous filament impairment. ${ }^{12,13}$

Besides the histopathological examination, the diagnosis of sarcoidosis is based on the compatible clinical and radiological picture (if the lungs are compromised). Differential diagnosis depends on the affected organs. In cases of cutaneous sarcoidosis, the important clinical and histopathological differential diagnosis are Hansen's disease, cutaneus tuberculosis, lupus vulgaris, deep mycoses, syphilis, foreign body granulomas and lymphocytic infiltrations. ${ }^{1,7}$
Chart 1: Clinical-laboratorial approach of suspected sarcoidosis cases

1. Clinical history - fever, emaciation, cough

2. Clinical exam - lungs, skin, eyes, liver and heart

3. Biopsy of easily accessed sites

4. Chest radiograph and lung function test

5. Eletrocardiogram

6. Ophtalmological evaluation

7. Biochemistry - liver and kidney evaluation / dosage

of serum and urinary calcium

Chart 1 shows the clinical-laboratorial approach to patients with clinical suspicion of sarcoidosis. ${ }^{7}$

The dosage of angiotensin converting enzyme produced by sarcoidal granuloma presents $10 \%$ of false-positive and $40 \%$ of false-negative. Therefore, it does not represent a specific exam and does not signal disease activity nor prognosi. ${ }^{7}$ The propaedeutics may be necessary for in-depth study of systemic involvement. High-resolution computerized tomography is cites for lung sarcoidosis cases, magnetic resonance for neurological, muscular, visceral and lacrimal glands involvement, in addition to scintigraphy with gallium-67 for cardiac sarcoidosis. ${ }^{14}$

Sarcoidosis may have spontaneous resolution, making the doubt about when to treat the patient controversial. The option for the treatment should consider both the extent and severity of symptoms, as well as the possibility of disease progression with loss of function of affected organs. As for skin lesions, the chance of disfigurement is the treatment indication, since it makes quality of life improvement possible. Corticoids are considered the first treatment option. Topical corticoids, either occlusive or intralesional are the best choice in cutaneous sarcoidosis restricted to a few lesions. Systemic therapy with corticoid for cutaneous sarcoidosis is reserved for patients presenting a severe illness, disseminated or refractory to topical treatment. ${ }^{7,15}$

Other drugs may be employed, such as methotrexate, antimalarial, azathioprine, chlorambucil, cyclophosphamide, cyclosporine, pentoxiphyline and even infliximab with good response. ${ }^{1,7,15} \square$ 


\section{REFERENCES}

1. Bolognia JL, Lorizzo JL, Rapini RP. Dermatology. 2nd ed. vol 2 .London: Mosby Elsevier; 2008.

2. Hem E. Boeck's sarcoidosis: a centennial. Int J Dermatol. 2000;39:545-9.

3. Samtsov AV. Cutaneous sarcoidosis. Int J Dermatol 1991;31:385-91.

4. Bethlem NM. Epidemiology of sarcoidosis in Brazil. Sarcoidosis. 1985;2:162.

5. Corrêa da Silva LC, Hertz FT, Cruz DB, Caraver F, Fernandes JC, Fortuna FP, et al. Sarcoidose no sul do Brazil: estudo de 92 pacientes. J Bras Pneumol. 2005;31:398-406.

6. Nunes H, Soler P, Valeyre D. Pulmonary sarcoidosis. Allergy. 2005;60:565-82.

7. Daldon PEC, Arruda LHF. Granulomas não infecciosos: sarcoidose. An Bras Dermatol. 2007;82:559-71.

8. Ahmed I, Harshad SR. Subcutaneous sarcoidosis: is it a specific subset of cutaneous sarcoidosis frequently associated with systemic disease? J Am Acad Dermatol. 2005;54:55-60.

9. Manã J, Marcoval J, Graells J, Salazar A, Peyri J, Pujol R. Cutaneous involvement in sarcoidosis: relationship to systemic disease. Arch Dermatol. 1997;133:882-8.

10. Mulinari-Brenner F, Badziak D, Rosas FMB, Fillus J, Moritz S. Alopecia: manifestação cutânea rara de sarcoidose. An Bras Dermatol. 2008;83:437-40.

11. Almeida Jr. HL, Jannke HA. Sarcoidose em cicatrizes prévias. An Bras Dermatol. 2004;79:79-82.

12. Weedon D. Skin pathology. $2^{\text {nd }}$ ed. London: Churchill Livingstone; 2002.
13. Mckee PH, Calonje E, Granter SR. Pathology of the skin with clinical correlations. $3^{\text {rd }}$ ed. Philadelphia: Elsevier Mosby; 2005.

14. Koyama T, Ueda H, Togashi K, Umeoka S, Kataoka M, Nagai S. Radiologic manifestations in various organs. Radiographics. 2004;24:87-104.

15. Cox CE, Davis-Allen A, Judson MA. Sarcoidosis. Med Clin North Am. 2005;89:817-28.

\author{
MAILING ADDRESS: \\ Diego Santos Rocha \\ Boulevard Vinte e Oito de Setembro, 87 \\ Vila Isabel \\ 20551-030 Rio de Janeiro, RJ \\ E-mail:dieg_rocha@yaboo.com.br
}

How to cite this article: Rocha DS, Presotto C, Bringel DM, Bomm L, Balassiano E, Alves MFGS. Sarcoidosis simulating syringomas. An Bras Dermatol. 2012;87(2):309-12. 